EDUCATIONAL NOTES.

National Hospital, Queen Square, Medical School.-A Post-Graduate Course on Diseases of the Nervous System will be held at the above Hospital from February 3 to March 28, 1930 .

The General Course will consist of 32 Clinical Lectures and Demonstrations at 3.30 p.m. each week-day, except Wednesday and Saturday. Teaching in the Out-Patient Department on each week-day except Saturday at 2 p.m.; and eight Pathological Lectures and Demonstrations on Mondays at 12 noon. The Fees for this Course will be $€ 66$ s.

A Course of eight Lectures on the Anatomy and Physiology of the Nervous System will be arranged on Fridays at 12 noon if there are sufficient applicants. Fee $£ 22 s$.

A Course of twelve Clinical Demonstrations chiefly on Methods of Examination of the Nervous System will be given on Tuesdays and Thursdays at 12 noon. Fee $£_{2} 2 s$.

Mr. Armour and Sir Percy Sargent operate at the Hospital on Tuesday and Friday mornings at 9 a.m. or at such other times as may be announced.

Any part of the Course may be taken separately. Special arrangements will be made for those unable to take the whole Course.

Tickets entitling to attend the Out-Patients' Clinic only ( $\oint_{2} 2 s$. for 3 months) may be obtained from the Secretary. A limited number of Students can be enrolled as Ward Clerks. Fees : $€ 5$ 5s. three months; $€ 775$. six months; $£$ ro ros. Perpetual Ticket. Applications should be addressed to the Secretary, Medical School, National Hospital, Queen Square, London, W.C. r.

For further particulars apply at the Hospital to Dr. J. G. Greenfield, Dean of the Medical School.

The Tavistock Square Clinic for Functional Nervous Disorders, 51, Tavistock Square, W.C. 1.-A Course of eight Lectures will be given at the Friends' House, Euston Road, N.W. I (opposite Euston Station), on Wednesdays, beginning January 29, I930, at 6 p.m., on Personality : Its Constitution, by R. G. Gordon, M.D., F.R.C.P.E., Royal United Hospital, Bath ; Its Problems, by J. R. Rees, M.D., Deputy Director, Tavistock Square Clinic.

Fee for the Course, $£ \mathrm{I}$ is. Single Tickets at $5 s$. will be issued in far as accommodation permits. Tickets for the course must be obtained in advance from the Hon. Lecture Secretary at 5I, Tavistock Square, W.C. I.

\title{
THE ESSENTIAL STRUCTURAL REQUIREMENTS OF A COLONY FOR
} MENTAL DEFECTIVES.

The Board of Control, with the approval of the Minister of Health, have appointed a. Committee with the following terms of reference: "To consider and report what are the essential structural requirements of a complete colony for mental defectives of all types, and to what extent the cost could be reduced by the adoption of semi-permanent or temporary buildings or other new methods of construction, having regard to the comparative cost of maintenance as well as the initial capital expenditure involved."

The Committee is constituted as follows: Walter Hedley, Esq., D.S.O., K.C., Rccorder of Newcastle-on-Tyne (Chairman) ; Mrs. F. Rose Davies, J.P., Alderman, Glamorgan County Council; Miss Clara Martineau, J.P., Member of the Birmingham City Council; Sir George Oatley, F.R.I.B.A.; Dr. A. Rotherham, Commissioner of the Board of Control; A. Scott, Esq., M.B.E., A.R.I.B.A., Chief Technical Officer, Ministry of Health ; Sir Lindsey Smith, J.P., Chairman of the Board of Governors of Holloway Sanatorium; F. Douglas Turner, Esq., M.B., Medical Superintendent of the Royal Eastern Counties Institution, Colchester.

Mr. H. J. Clarke, of the Board of Control, will act as Secretary. 